\title{
Anti Solar Activity of Costus Speciosus Leaves of Sikkim Himalayas: Effects of Time \& Temperature on Extraction Process
}

\author{
Prasenjit Mitra ${ }^{1}$, Tanaya Ghosh ${ }^{2}$, Prasanta Kumar Mitra ${ }^{3 *}$
}

${ }^{1}$ Department of Biochemistry, All India Institute of Medical Sciences (AIIMS), Basni Industrial Area, MIA 2nd Phase, Basni, Jodhpur, Rajasthan 342005, India

${ }^{2}$ Department of Medical Biotechnology, Sikkim Manipal University, Sikkim Manipal Institute of Medical Sciences, Gangtok, Sikkim, India

${ }^{3}$ Professor \& Head, Department of Medical Biotechnology, Sikkim Manipal University, Sikkim Manipal Institute of Medical Sciences, Gangtok, Sikkim, India

DOI: $10.36347 /$ sajp.2020.v09i01.003

| Received: 06.01.2020 | Accepted: 13.01.2020 | Published: 16.01.2020

*Corresponding author: Prasanta Kumar Mitra

Abstract

Original Research Article

It is known that pharmacological action of a plant depends on time and temperature of extraction process. Recently we have noted anti solar activity of ethanol extract of Costus speciosus (C. speciosus) leaves of Sikkim Himalayas. Aim of the present work was to note effects of time and temperature of the extraction process on anti solar activity of $C$. speciosus leaves. $C$. speciosus leaves were collected from the local market and identified by the taxonomist. Ethanol extracts of the leaves were prepared for $15,30,45,60$, minutes at temperatures 30, 40, 50, 60 degree centigrade. Anti solar activity of different extracts was checked by a spectrophotometer taking absorption in UV region (200 - 400 $\mathrm{nm})$. Results showed that ethanol extract of $C$. speciosus leaves of 15 minutes at $40^{\circ} \mathrm{C}$ showed maximum anti solar activity. These conditions may be maintained for isolation of the anti solar compound from C. speciosus leaves.

Keywords: Costus speciosus leaves; Solvent extractions; Time; Temperature; Anti solar activity.

Copyright @ 2020: This is an open-access article distributed under the terms of the Creative Commons Attribution license which permits unrestricted use, distribution, and reproduction in any medium for non-commercial use (NonCommercial, or CC-BY-NC) provided the original author and source are credited.

\section{INTRODUCTION}

Extraction process is carried out to demonstrate biological / pharmacological activities of a plant or isolation of active substances from plants and other sources. Time of extraction has great influence on the extracting material. Mahmoud et al. showed that forty five minutes extraction was needed to get maximum antioxidant activity of one species of Lavandula [1]. Effect of duration time of maceration on nitrate content of Vernonia cinerea (L.) was studied by Chaowalit and Chitradee [2]. Authors opined that sixty minute maceration time is needed to get maximum nitrate from $V$. cinerea. Intan et al. studied effect of time on the extraction of phenolic compounds and the anti-radical activity of Clinacanthus nutans Lindau leaves. The authors observed that an extraction time of $120 \mathrm{~min}$ is needed to get maximum phenolic compounds thereby the anti-radical activity of $C$. nutans Lindau leaves [3].

Temperature has also a considerable effect on the rate of extraction of active compounds from plants or other sources. Wingard and Phillips studied effect of temperature the rate of extraction of crude oils from vegetable oil seeds with solvents and noted that rate of extraction varied with temperature [4]. Effect of extraction temperature on the extraction of phenolic compounds from Orthosiphon stamineus leaves was studied by Amir et al. Authors stated that a temperature of $160^{\circ} \mathrm{C}$ is required for optimum extraction of phenolic compounds from $O$. stamineus leaves [5]. Tan et al., studied effects of temperature on extraction process of total phenolic content of henna (Lawsonia inermis) stems and observed that $55^{\circ} \mathrm{C}$ temperature was most suitable for extraction process to collect maximum amount of phenolic compounds from henna [6].

C. speciosus (family, Costaceae) is an erect perennial herb [7] found in moist tropical evergreen forests [8]. The plant is edible. Other names of the plant are Channakoova in Malayalam, Kostam in Tamil, keu in Bengali and Hindi, Kashmeeramu in Telegu, Kembuka in Sanskrit, Paskarmula in Guajarati, Tara in Assamese, Spiral flag in English etc [9]. Since long $C$. speciosus is used in traditional medicine as drug for skin diseases, cough and cold, rheumatism, diarrhea, fever, bronchial asthma, dysentery, dyspepsia, pneumonia, dropsy, urinary diseases etc [10]. $C$. speciosus has also vast pharmacological activities like anti cancer, anti-inflammatory, anti oxidant, anti 
bacterial, anti fungal, anti diabetic, antipyretic, antifertility etc $[11,12]$.

Recently, we have shown anti solar activity of ethanol extract of $C$. speciosus leaves. Aim of the present work was to see effects of time and temperature on the extraction process to get maximum anti solar activity of $C$. speciosus leaves.

\section{MATERIAL AND METHODS Plant Material}

Leaves of $C$. speciosus were collected from the local market during June - July and authenticated by the taxonomist of the department of Botany of the University of North Bengal, Siliguri. A voucher specimen (No.SM-MB-011) was kept in the department of Medical Biotechnology, Sikkim Manipal Institute of Medical Sciences of Sikkim Manipal University, Gangtok, Sikkim, India for future reference.

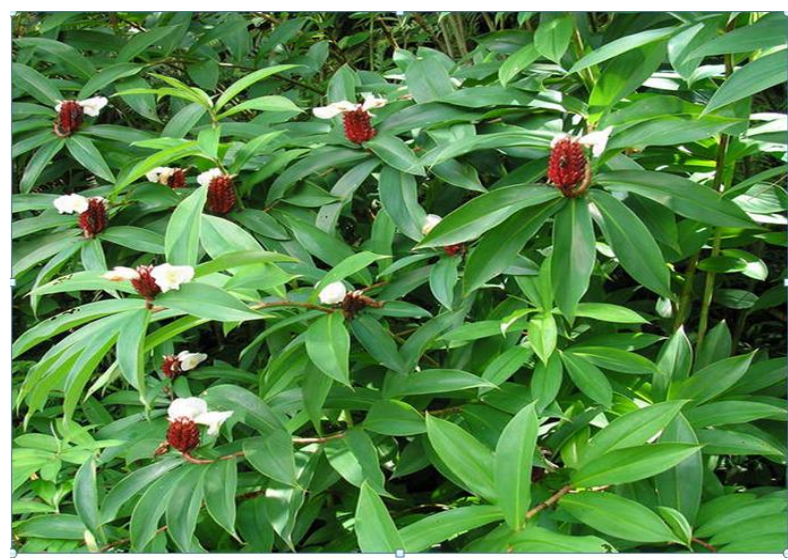

Fig-1: Costus speciosus leaves

\section{Test Drug}

Leaves of $C$. speciosus were washed thoroughly under tap and then by distilled water. Leaves were then shed dried and powered. The powder, used as test drug, was stored desiccated at $4{ }^{0} \mathrm{C}$ until further use.

\section{Solvent Extraction}

Test drug $(100 \mathrm{~g})$ was extracted with $500 \mathrm{ml}$ of ethanol. Ethanol was chosen as solvent because in our earlier experiments we noted that ethanol extract of $C$. speciosus leaves had maximum anti solar activity.

\section{Effect of time on extraction process}

Extraction processes were done separately for $15,30,45$ and 60 minutes.

\section{Effect of temperature on extraction process}

In separate experiments extraction processes were conducted at 30, 40, 50 and 60 degree centigrade.
The extract was filtered and the filtrate was evaporated to dryness in vacuo with rotary evaporator. This was applied separately for all extracts. Brown masses obtained.

\section{Anti solar activity}

$10 \mathrm{mg}$ of this mass was dissolved in $100 \mathrm{ml}$ distilled water. The solution was processed in a spectrophotometer for UV ray absorption at the range of 200-400 nm.

\section{Chemicals}

Chemicals required for the study were purchased from Loba Chem. Lab, Himedia Lab, India and from Merck, Germany

\section{STATISTICAL ANAL YSIS}

All experiments were conducted for three times. Data were analysed statistically by SPSS 20 . The statistical significance between UV absorption spectra of different extracts was evaluated with Duncan's multiple range test (DMRT). $5 \%$ were considered to be statistically significant [13].

\section{RESULTS}

Effect of time on extraction process for determination of anti solar activity of C. speciosus leaves is shown in Table -1 . UV ray absorptions of 15 minutes ethanol extract of $C$. speciosus leaves at 200 $\mathrm{nm}, 250 \mathrm{~nm}, 300 \mathrm{~nm}, 350 \mathrm{~nm}$ and $400 \mathrm{~nm}$ were 1.4, $0.91,0.86,0.77,0.62$ respectively. For $30 \mathrm{~min}$ extraction time the values came $1.3(200 \mathrm{~nm}), 0.90(250$ $\mathrm{nm}), 0.84(300 \mathrm{~nm}), 0.75(350 \mathrm{~nm})$ and $0.60(400 \mathrm{~nm})$. UV ray absorptions of 45 minutes ethanol extract of $C$. speciosus leaves at $200 \mathrm{~nm}, 250 \mathrm{~nm}, 300 \mathrm{~nm}, 350 \mathrm{~nm}$ and $400 \mathrm{~nm}$ were $1.4,0.90,0.85,0.76,0.61$ respectively and for $60 \mathrm{~min}$ extraction time the values came 1.3 (200 $\mathrm{nm}), 0.92(250 \mathrm{~nm}), 0.87(300 \mathrm{~nm}), 0.75(350 \mathrm{~nm})$ and $0.58(400 \mathrm{~nm})$.

Effect of temperature on extraction process for determination of anti solar activity of $C$. speciosus leaves is shown in Table -2 . UV ray absorptions of ethanol extract of C. speciosus leaves at $30^{\circ} \mathrm{C}$ for 15 min were $1.0,0.81,0.73,0.67,0.50$ at $200 \mathrm{~nm}, 250 \mathrm{~nm}$, $300 \mathrm{~nm}, 350 \mathrm{~nm}$ and $400 \mathrm{~nm}$ respectively. For temperature $40^{\circ} \mathrm{C}$ under same conditions values came $1.2(200 \mathrm{~nm}), 0.90(250 \mathrm{~nm}), 0.86(300 \mathrm{~nm}), 0.75(350$ $\mathrm{nm})$ and $0.60(400 \mathrm{~nm}) . \mathrm{UV}$ ray absorptions of ethanol extract of $C$. speciosus leaves at $50^{\circ} \mathrm{C}$ for 15 min were $1.2,0.90,0.85,0.75,0.58$ at $200 \mathrm{~nm}, 250 \mathrm{~nm}, 300 \mathrm{~nm}$, $350 \mathrm{~nm}$ and $400 \mathrm{~nm}$ respectively. For temperature $60^{\circ} \mathrm{C}$ under same conditions values came $1.2(200 \mathrm{~nm}), 0.91$ $(250 \mathrm{~nm}), 0.76(300 \mathrm{~nm}), 0.74(350 \mathrm{~nm})$ and $0.60(400$ $\mathrm{nm})$. 
Table-1: Anti solar activity of ethanol extract of $C$. speciosus leaves: Effect of time on extraction process

\begin{tabular}{|c|l|l|}
\hline Solvent & Time (minutes) & Anti solar activity $($ absorptions at 200/ 250/ 300/ 350/ 400 nm) \\
\hline Ethanol & 15 & $1.4 / 0.91 / 0.86 / 0.77 / 0.62$ \\
& 30 & $1.3 / 0.90 / 0.84 / 0.75 / 0.60$ \\
& 45 & $1.4 / 0.90 / 0.85 / 0.76 / 0.61$ \\
& 60 & $1.3 / 0.92 / 0.87 / 0.75 / 0.58$ \\
\hline
\end{tabular}

Table-2: Anti solar activity of ethanol extract of $\boldsymbol{C}$. speciosus leaves: Effect of temperature on extraction process

\begin{tabular}{|l|l|l|}
\hline Solvent & Degree centigrade & Anti solar activity (absorptions at 200/ 250/ 300/ 350/ 400 nm) \\
\hline Ethanol & 30 & $1.0 / 0.81 / 0.73 / 0.67 / 0.50$ \\
& 40 & $1.2 / 0.90 / 0.86 / 0.75 / 0.60$ \\
& 50 & $1.2 / 0.90 / 0.85 / 0.75 / 0.58$ \\
& 60 & $1.2 / 0.91 / 0.76 / 0.74 / 0.60$ \\
\hline
\end{tabular}

\section{DISCUSSION}

It appears from figure -2 that ethanol extracts of $C$. speciosus leaves for the periods of $15 \mathrm{~min}, 30$ min, $45 \mathrm{~min}$ and $60 \mathrm{~min}$ exert anti solar activity. All extracts absorbed UV rays at $250 \mathrm{~nm}, 300 \mathrm{~nm}, 350 \mathrm{~nm}$ and $400 \mathrm{~nm}$ wave lengths. Maximum absorption, however, was found at $200 \mathrm{~nm}$. It was also found that UV ray absorption values of 15 min ethanol extract of C. speciosus leaves were comparatively higher than that of $30 \mathrm{~min}, 45 \mathrm{~min}$ and $60 \mathrm{~min}$ ethanol extracts but the values were not statistically significant (Figure-3).

Figure-4 indicates effect of temperature of ethanol extract of $C$. speciosus leaves on anti solar activity. Ethanol extracts done at $30^{\circ} \mathrm{C}, 40^{\circ} \mathrm{C}, 50^{\circ} \mathrm{C}$ and $60^{\circ} \mathrm{C}$ absorbed UV rays at $200 \mathrm{~nm}, 250 \mathrm{~nm}, 300$ $\mathrm{nm}, 350 \mathrm{~nm}$ and $400 \mathrm{~nm}$ wave lengths. Maximum absorption for all extracts was found at $200 \mathrm{~nm}$. Ethanol extract of C. speciosus leaves done at $40^{\circ} \mathrm{C}$ had more $\mathrm{UV}$ ray absorption capacity than that of $30^{\circ} \mathrm{C}$ extract but the results were not statistically significant. Ethanol extract of C. speciosus leaves done at $50^{\circ} \mathrm{C}$ and $60^{\circ} \mathrm{C}$ had more or less same UV ray absorption capacity when compared with that of ethanol extract done at $40^{\circ}$ C (Figure-5).

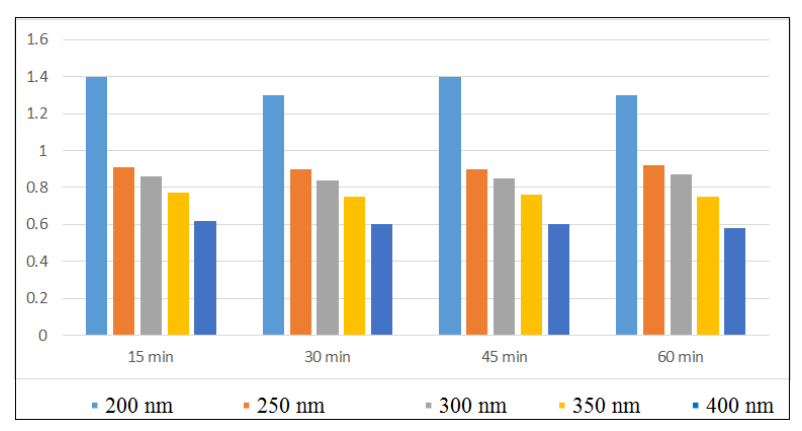

Fig-2: Anti solar activity of ethanol extract of $C$. speciosus leaves: Effect of time on extraction process

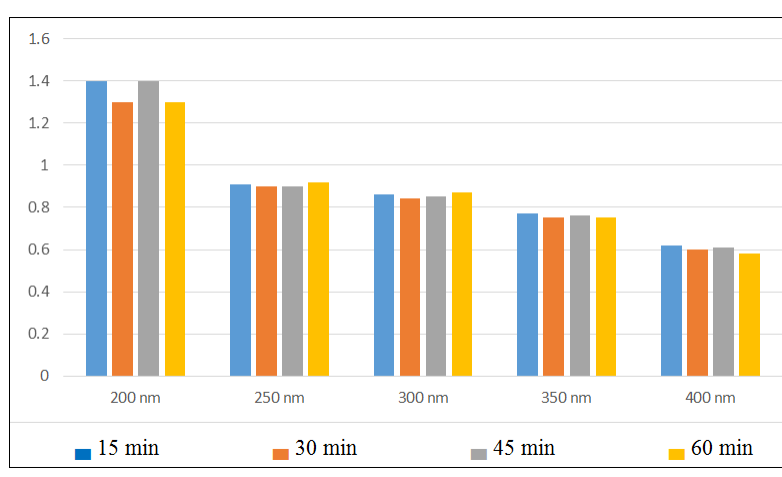

Fig-3: Comparison of anti solar activity of time based ethanol extract of $C$. speciosus leaves

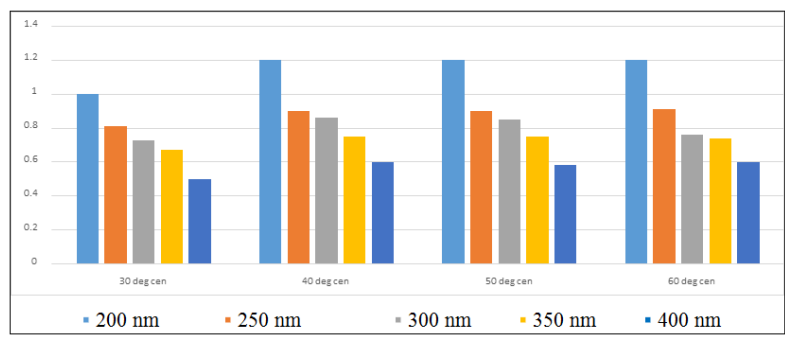

Fig-4: Anti solar activity of ethanol extract of $C$. speciosus leaves: Effect of temperature on extraction process

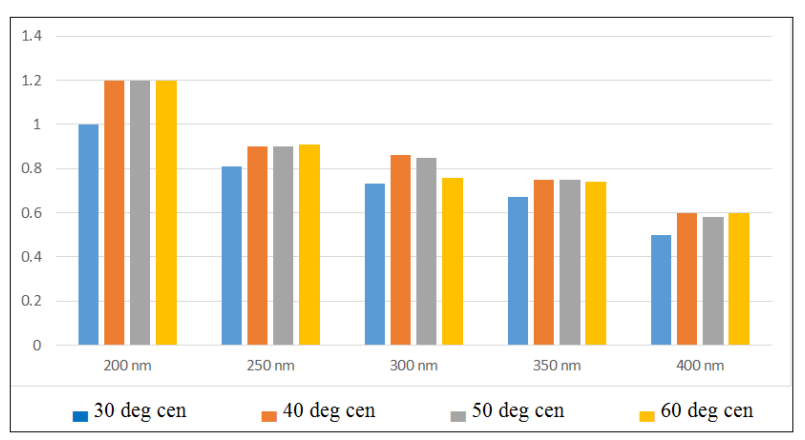

Fig-5: Comparison of anti solar activity of temperature based ethanol extract of $C$. speciosus leaves

Reports are available on effect of time and temperature on extraction process [1-6]. In the present work we found that ethanol extract of $C$. speciosus leaves for a period of $15 \mathrm{~min}$ at temperature $40^{\circ} \mathrm{C}$ had maximum UV ray absorption capacity. 
UV ray is both good and bad for human body. It is needed for synthesis of vitamin D which helps to maintain strong bones. Humans get cutaneous synthesis of vitamin $\mathrm{D}$ from solar UV-radiation. This covers almost $90 \%$ of the vitamin $\mathrm{D}$ requirement in human body. Solar UV radiation is, therefore, good for humans. But this radiation has bad effect too. Skin is severely affected if there is over exposure of UV rays. Pigmentary changes atrophy, wrinkling and malignancy may occur. Basal cell carcinoma or malignant melanoma and skin cancer like squamous cell carcinoma may develop. Solar UV-radiation can cause eye and skin injury, stimulate genetically determined photo sensitivities and photosensitivity reactions to ingested drugs. UV radiation also affects eye. Cornea, the outer protective coating of the eye, may be affected. Painful inflammation of eye is seen and if the eye gets chronic UV exposure, then it lead to formation of cataracts. Over-exposure to UV radiation also changes distribution and function of white blood cells in human body. This may cause harmful suppressing effect on the immune system $[14,15]$.

Under the circumstances efforts are going on to search the sources which can absorb UV radiation. Medicinal plants were found the good source. Many medicinal plants like Lycopersicon esculantum, Oscimum sanctum, Azadirachta indica, Mentha piperita, Calotropis gigantean, Aloe vera, Carica papaya, Phyllostachys pubescens etc. are now known which can absorb solar UV radiation [16, 17]. Present work has included $C$. speciosus in the list of medicinal plants responsible for absorption of solar UV radiation.

It is known that biological activity of medicinal plants varies with season [18-20]. We are now interested to see the effect of season on solar UV radiation absorption by $C$. speciosus leaves. Work is going on in our laboratory in this direction.

\section{CONCLUSION}

Present study confirmed extraction time and temperature for preparation of ethanol extract of $C$. speciosus leaves required for maximum UV radiation absorption. The methodology may be utilized in preparation of sun screen lotions to protect humans from UV radiation.

\section{ACKNOWLEDGEMENTS}

We gratefully acknowledge the cooperation of taxonomists of the department of Botany, University of North Bengal, Siliguri, Dist. Darjeeling, and West Bengal for identification of $C$. speciosus leaves.

\section{Conflict of interest: Nil}

\section{REFERENCES}

1. Mustapha Mahmoud DI, Fawzia TB, Banyahia M, Bouazza S, Benyamina A, eddine Mahi D. Effect of time and traditional extraction on antioxidant activity of three Lavandulaspecies. Global Journal ofMedicinal Plant Research. 2016;4(3):6-8.

2. Monton C, Luprasong C. Effect of Temperature and Duration Time of Maceration on Nitrate Content of Vernonia cinerea (L.) Less.: Circumscribed Central Composite Design and Method Validation. International journal of food science. 2019;2019.

3. Sulaiman IS, Basri M, Masoumi HR, Chee WJ, Ashari SE, Ismail M. Effects of temperature, time, and solvent ratio on the extraction of phenolic compounds and the anti-radical activity of Clinacanthus nutans Lindau leaves by response surface methodology. Chemistry Central Journal. 2017 Dec;11(1):54.

4. Wingard MR, Phillips RC. Solvent extraction IV. The effect of temperature on extraction rate. Journal of the American Oil Chemists' Society. 1951;28: 149-152.

5. Amir Hamzah NA, Morad NA, Nordin MFM, Ilia Anisa AN, Yusof YAM. Effect of extraction time and temperature on the extraction of phenolic compounds from Orthosiphon stamineus leaves. Aust. Journal Basic \& Appl Sci. 2017; 11(3): 1521.

6. Tan MC, Tan CP, Ho CW. Effects of extraction solvent system, time and temperature on total phenolic content of henna (Lawsonia inermis) stems. International Food Research Journal. 2013; 20(6): 3117-3123.

7. Gupta AK, Tondon N, Sharma M. Quality Standards of Indian Medicinal Plants, Medicinal Plants Unit, Published by Indian Council of Medical Research, 2008; 7:48.

8. Gupta RK. Medicinal and Aromatic Plants, CBS Publishers and Distributors, New Delhi. 2010; 499.

9. Swati S, Agarwal P. Kebuka (Costus Speciosus): A critical review. World Journal Pharm Pharm Sci, 2015; 4: 421-31.

10. Srivastava S, Singh P, Mishra G, Jha KK, Khosa RL. Costus speciosus (Keukand): A review. Der Pharmacia Sinica. 2011; 2(1):118-128.

11. Bhattacharya SK, Parik AK, Debnath, PK, Pandey, VB, Neogy, NC. Anticholinesterase activity activity of Costus speciosus alkaloids. Indian Journal Pharmacol. 1972; 4:178-178.

12. El-Far AH, Shaheen HM, Alsenosy AW, El-Sayed YS, Al Jaouni SK, Mousa SA. Costus speciosus: Traditional Uses, Phytochemistry, and Therapeutic Potentials. Pharmacognosy Reviews. 2018 Jan 1;12(23):120-127.

13. Bliss CI. Statistics in biology, Statistical methods for research in the natural Sciences, Vol. 1, McGraw Hill Book Company, NY. 1967: 558.

14. MacKie RM. Effects of Ultraviolet Radiation on Human Health. Radiation Protection Dosimetry. 2000; 91(1-3):15-18. 
15. Harge VG, Yadav A. Study of Methanolic Extract of Leaves Calotropis gigantean (L.) As an AntiSolar. Adv Complement Alt Med. 2018; 1(4):101111.

16. Gupta D. Absorbing Properties of Some Plant Derived Extracts. Research Journal of Chemical and Environmental Sciences. 2013; 1(2) : 34-36.

17. Gupta V. Environment friendly antibacterial and uv protective finish on cotton using S. cumini (1.) leaves extract. International Journal of Textile and Fashion Technology. 2017; 7(1): 53-62.
18. Feeny P. Seasonal changes in oak leaf tannins and nutrients as a cause of spring feeding by winter moth caterpillars. Ecology. 1970; 51: 565-581.

19. Gupta PL. Variation in morphological characters and active principle constituents of Eclipta prostrata Linn. Under different seasonal and soil conditions. JRIM.1977; 12(1): 80-84.

20. Mauffette Y, Oechel WC. Seasonal variation in leaf chemistry of the coast live oak Quercus agrifolia and implications for the California oak moth. Phryganidia californica Oecologia. 1989;79:439-445. 